\title{
Organisational Culture and Knowledge sharing in the Czech Settings: A Survey- based Pragmatic Review
}

\author{
Richard Brunet-Thornton ${ }^{1}$, Vladimír Bureš ${ }^{2}$, Tereza Otčenášková ${ }^{3}$ and Fridrich \\ Racz $^{4}$ \\ 1, 2, 3 University of Economics Prague, Prague, Czech Republic \\ ${ }^{4}$ Vysoká škola manažmentu, Bratislava, Slovakia
}

Correspondence should be addressed to: Tereza Otčenášková; tereza.otcenaskova@uhk.cz

Received date: 5 october 2015; Accepted date: 7 January 2016; Published date: 4 March 2016

Academic Editor: Monica Boldea

Copyright @ 2016. Richard Brunet-Thornton, Vladimír Bureš, Tereza Otčenášková and Fridrich Racz. Distributed under Creative Commons CC-BY 4.0

\begin{abstract}
Knowledge sharing represents one of the main knowledge processes intensively studied and developed by both academicians and practitioners. This process is apparently influenced by many factors, where organisational culture possesses a leading position. Therefore, this manuscript analyses the mutual interrelationship between corporate culture and knowledge dissemination within organisations. Organisational frameworks and corporate culture classifications are reviewed based on their inherent compatibility with knowledge sharing. This discussion further elaborates a recent study and its findings focused on the knowledge management experience in the Czech Republic and knowledge sharing practices in selected Czech universities. The main objective of the paper is to emphasise selected questions associated with a knowledge sharing culture and open debate on these issues.
\end{abstract}

Keywords: Corporate Culture - Czech Knowledge Management Experience - Knowledge Management - Knowledge Sharing

\section{Introduction}

Today, the development and application of new knowledge is essential for the survival of almost all businesses. Many reasons might be identified to support this argument. First, current economy is closely connected with intangible products. Ideas, processes, or information are taking a growing share of global trade from the traditional manufacturing economy connected to tangible products. Second, knowledge and related continuous innovation are increasingly considered as the only sustainable competitive advantage. Third, the turnover of staff is quite increasing. Nowadays, people do not have a job for life very often. Understanding that knowledge leaves with a person leaving the organisation 
represented one of the main driving forces for knowledge management initiative that took place decades ago. Four, no matter whether it is a large global or small geographically dispersed organisation, all firms have to cope with the fact that they 'do not know what they know'. Expertise learnt and applied in one part of the organisation is not always leveraged in another. Last, there is a strong acceleration of change in technology, business and social environment. Concurrently with changes of environment, our knowledge base erodes. At a certain level of generalisation - in some businesses, the majority of what you knew several years ago is probably obsolete today. Due to all these reasons, knowledge sharing represents one of the main knowledge processes that is intensively investigated in both business and academic circles (Eisenhardt and Santos, 2002). The reason is quite simple, knowledge sharing is considered to be a vital element for innovation, organisational learning, skills and competencies development, increased productivity, and competitive advantage (Mooradian et al., 2006). No matter how the programme is recognised within the enterprise, whether it is known as an intranet café, management success stories or a lessons learnt repository, organisations aspire to improve performance and subsequently, competitiveness through varying degrees of Knowledge Management (KM) implementation and deployment (Milosz and Milosz, 2010; Martín et al., 2012). Since the dawn of the concept of "the knowledge worker" (Drucker, 1996), corporations have demonstrated interest in this concept of voluntary knowledge sharing. Knowledge in all its forms influences whether the business succeeds or fails (Bureš and Brunet-Thornton, 2009). This practice is most common in what is considered leading edge such as, telecommunications (Martín et al., 2012) and aeronautics (Shan et al., 2013). With the mandate to preserve, enhance, and deploy knowledge within an enterprise, there must exist a prerequisite of a functional system of knowledge sharing and transfer, if not at a formal level then certainly, informal. Although the terms Knowledge Sharing (KS) and Knowledge Transfer (KT) are often used synonymously, they denote distinct activities (Brunet-Thornton and Bureš, 2012). Consequently, organisational members whether management or nonmanagement, despite their level of seniority, must comprehend these principles. It is therefore necessary that KM is an integral part of the corporate culture that integrates KS (Brunet-Thornton and Bureš, 2013).

Despite the many priorities that confront the operational manager, an additional task entails the promotion of knowledge sharing within their respective teams. Organisational behavioural studies continue to report that in environments that exhibit mistrust or anxiety, employees retain knowledge and information for their own utilisation and are reluctant to share (Zaghloul and Hartman, 2003). Fear of job loss motivates the workers to view knowledge as security and a competitive advantage over their colleagues. This personal strategy, although considered by the individual as a self-defence mechanism, endangers the further development of the organisation with possibly disastrous effects on all organisational members.

The objective of this discussion is to analyse issues relative to organisational culture and the possibilities to share knowledge. It promotes a specific perspective on knowledge sharing based on a literature review, previous research and personal reflection of experiences in the workplace. From a methodological viewpoint, the experiences are documented based on the cultural frameworks reviewed. This manuscript serves both as a conceptual as well as research work from which the authors aspire to open debate on the issues associated with KM deployment and the need for further research within the discipline.

\section{Literature Review and Problem Statement}

This section briefly exemplifies research studies relevant to the content of this manuscript. Only few studies focus on interaction among organisations (Bureš et al., 2012). Most KM literature concentrates on the organisational level that includes strategic alliances, expectations and trust; the individual level comprises motivation, 
organisational antecedents and the like (Mueller, 2014). From these sources, it is commonly believed that organisational culture serves as basis for effective KM and organisational learning (Choo et al., 2008). Organisational culture in itself is a complex series of concepts that includes numerous issues as well as theoretical frameworks (Zheng et al., 2010). In essence, organisational culture is the source and embodiment of the values and belief systems that influence behaviour. Corporate culture "is the way we do business". Some aspects are more fundamental than others and are regarded as essentials such as, employee compensation and benefits, educational and motivational programmes, corporate branding and infrastructure. Corporate culture generates the overall atmosphere in the enterprise and in doing so, projects the corporate identity both within the organisation as well as externally.

Considering the current literature, several classifications of corporate culture, usable for investigation of its interrelationship with knowledge sharing, might be identified. For instance, Cameron and Quinn (1999) have developed an organisational cultural framework based on a theoretical model called the "Competing Values Framework". They identify four types of organisational culture: Clan, Adhocracy, Market, and Hierarchy:

- Clan oriented cultures are like families focused on mentoring, nurturing, and "doing things together". Apparently, knowledge sharing mostly represents a natural and inherent aspect of this type of culture.

- Adhocracy oriented cultures are dynamic and entrepreneurial. These are concentrated on risk-taking, innovation, and "doing things first".

- Market oriented cultures are oriented to results with the emphasis on competition, achievement, and "getting the job done". Knowledge sharing can be mostly seen as a source for evaluation and assessment.

- Hierarchy oriented cultures are structured and controlled, with a focus on efficiency, stability and "doing things right". There are predefined directions of knowledge flows and knowledge itself is mostly used as a criterion for ratings.

Next, Harrison (1972), the first researcher who developed a typology of "organisational ideologies" that affect behaviours and organisational change efforts, defined four different kinds of culture. These comprise Power culture, Role culture, Task culture, and Person culture:

- In an organisation with a power culture, power is held by just a few individuals whose influence spreads throughout the organisation. There are a few rules and regulations taking place (those with power decide what happens and what type of knowledge is required and valuable).

- Organisations with a role culture are closely tied with various rules. These companies are highly controlled, with everyone in the firm knowing what their roles and responsibilities are. Power in a role culture is determined by a person's position (role) in the organisational structure and the specific knowledge he or she possesses.

- Task culture is developed when teams in an organisation are established to address (knowledge-) specific issues or progress projects. The task is the important thing, so power within the team will often shift depending on the mix of the team members and the status of the problem or project.

- In organisations with person cultures, individuals very much consider themselves as special and superior to the organisation. The company simply exists in order for people to work, share and apply knowledge. This type of organisation is really just a collection of individuals who work for the same organisation.

The last distinctive categorisation of corporate culture mentioned here includes the classification introduced by Deal and Kennedy (1982). It encompasses:

- Tough guy/macho culture that is individualistic with the employee at the centre. The environment is one of 
excitement and members eagerly seek advancement with its associated rewards. The worker is considered as good as their last performance review.

- Work hard/play hard culture prioritises the group. Ideas are appreciated but members are less prone to take risks. Team collaboration and determination are essential.

- Bet Your Company culture in which decision-making is frequent and often risky. Gains are frequently realised in the long-term rather than in the short-term.

- Process cultures as the name suggests concentrate on the method rather than the output.

From this cultural perspective, the 'workhard/play-hard' category appears to be the most approachable when compared with the other three. As the members concentrate their efforts on teams, there is more likely to be a greater sharing of knowledge within the team. However, they are risk avoidant that signifies a reliance on well-rehearsed routines that possibly limit innovation. This suggests a reverse process culture wherein the team is prone to concentrate on the product rather than the method. In this culture-type, multiple teams may compose business units or silos that also suggests the possibility of competition between each unit and team. These circumstances may promote KS within the respective groups but not with each other, or business unit.

Schein (2004) proposes a three-level organisational culture:

Level 1 - artefacts that include social environment, physical infrastructure, output, communication, group behaviour, in essence, the most visible aspects both tangible and intangible;

Level 2 - values based on circumstances of reality. From these values and beliefs members substantiate their actions and behaviours;

Level 3 - basic underlying assumptions that constitute lessons learnt wherein proven solutions to problems eventually become normal practice. In doing so, they impact member perceptions and behaviours.

Using Schein's categorisation, $\mathrm{KS}$ is applicable to all three levels. Nevertheless, it is most predominant at level 3 from when new solutions to problems are documented and shared to form artefacts (level 1); then communicated (level 1) to modify behaviours (level 2). Following which, they form a part of the normal operations in level 3. In this scenario, KS is both sequential and cyclical.

Out of the abovementioned organisational culture frameworks, it is the second one that presents the most challenges to KS. In a power culture, only the centre of the power is able to determine the need or forecast the benefits of KS. To a degree, decisions of this nature are politically dependent on the impact to the balance of influence. Within this culture type, power equates to influence; influence is the source of power. KS in this case may endanger power. Role culture is explicitly linked with expertise and specialisation; two major barriers to KS (Brunet-Thornton and Bureš, 2012). As the role that the individual fulfils is prioritised over the actual incumbent, another candidate with equivalent expertise is viewed as a threat. Task cultures, especially in project management roles, also enjoy a high level of expertise. Increasingly, associations offer certification courses to increase knowledge while providing the person with accreditations. Common examples include the Project Management Institute, and others. Although these organisations promote KS, they are often used individually as job security collateral. Person cultures serve the individual. Any overt signs of altruism are superficial to maintain a mutual cohesion to safeguard personal power.

\section{Key Findings}

As part of a study conducted to determine the relative state of Knowledge Management in the Czech Republic, two sets of self-administered questionnaires (SAQ) were circulated. The first SAQ consulted the business community at large and included the education sector. The purpose of this instrument was to gauge 
$\mathrm{KM}$ in general as an operational practice within the respondents' workplace. The second set concentrated on five institutions of higher learning. The format although comparable to the industry-centred instrument, sampled students and faculty on KS and KT. Nomenclature used for the general KM survey, Czech Knowledge Management Experience (CZ-KM-E) and for the university sample, Knowledge Sharing and Knowledge Transfer (KS/KT-CZUNI). Each instrument is prefaced with definitions to facilitate comprehension. CZKM-E provides definitions for Knowledge Management and Intellectual Capital, whereas KS/KT-CZUNI provides definitions for KM, KS, and KT.

\section{Czech Knowledge Management Experience}

KM remains a practice followed or acknowledged by an intimate minority (38\%). Within the latter, a substantial portion is from multinational enterprises, consulting firms, and government. There is a lack of 'knowledge' of the principles associated with KM or a general disinterest. Owner and/or board level are the promoters (48.8\%) and often concentrate on the IT level (34.5\%). There is a tendency to believe that all business units benefit from a KM programme. Nevertheless, HR and Sales benefit the most. There remains the question, however, that based on the definitions supplied and due to the lack of an overall appreciation of KM that many respondents assume a global benefit entailing the involvement of all. There is no time for KM $(81.5 \%)$ resounds throughout the results. The lack of funding (48.1\%) followed by information overload impede any KM implementation.

The study indicates that KM programmes are prevalent in larger enterprises, often affiliates or subsidiaries of multinationals. Those not working in a KM environment believe that such a programme is an asset to their organisation. Most have not considered a programme, whereas those that have are in the process of establishing. The state of KM in the Czech Republic is either in its infancy or in a state of dormancy waiting for recognition. Despite the claims and promises of the Czech government, KM remains relatively unknown. Even from those familiar with the concept, the initial impetus originates from board level suggesting that the process is imposed from headquarters. The obstacles identified to $\mathrm{KM}$ implementation are standard: no time to share, information overload, and an unwillingness to share (Dalkir, 2005). Girard and Allison (2008) propose that information overload leads to information anxiety. Wurman (1989) suggests that information anxiety leads to not understanding feelings of being overwhelmed by the sheer volume of information, questioning the existence of certain information, and not being able to locate the information in question. Even from within the usual scope of KM benefits, the often-cited increased revenues, customer service, and reduced costs attract medium to neutral appeal. Intranet and email account for the highest success rates in technology.

There is a lack of an overall plan in the development once implemented. The majority claim that they have no idea of what is to become of their programme or of KM. Ultimately, the following statement, 'the organisation does not demonstrate the relationship between the importance of KM and the achievement of organisational goals', captures the Czech response within an organisational framework. In sum, this demonstrates that $\mathrm{KM}$ as a concept let alone a practice remains unknown within Czech organisational culture.

In reference to Dalkir (2005), the respondent personal views reinforce the obstacles through the acclamation that knowledge equates to power and reduces job security. Opinion also reflects on the notions that this is a management fad $(67.6 \%)$ and is something that a computer does $(46.3 \%)$.

In this circumstance, systems thinking would be applicable, since as stated by Dalkir (2005), "KM is perhaps best categorised as a science of complexity". If it is to become a plausible asset to the Czech Republic, it must be simplified to connect with daily activities often taken for granted. There exists the option of personalising KM through Action Learning wherein individuals working with a team 
build on thought input starting with 'I think and I know' (Harris, 2005).

\section{Knowledge Sharing and Knowledge Transfer in Selected Czech Universities}

Respondents are evenly split (42.9\%) between those who agree and disagree as to whether or not the universities' KS and KT methods are effective. However, adding the corresponding number of responses of those who strongly disagree or strongly agree shifts the balance to those who disagree with the statement by $7.1 \%$. Therefore, fifty per cent do not believe that the existing KS and KT methods are effective.

However, even with an improved IT infrastructure, $\quad 33.3 \%$ would not participate more in discussions and sharing ideas. This leads one to the conclusion that the environment is not conducive to $\mathrm{KS}$ and KT. Results indicate that there is a lack of motivation through feedback and encouragement. $48.2 \%$ of respondents are not motivated and the same number feels that peers, professors (in this case students), and advisors (in both cases) do not provide feedback and encouragement to share knowledge during lectures and discussions. There is a lack of motivation to develop new ideas (46.4\%) as new ideas are not accepted at the university (51.8\%). One possible remedy $(51.8 \%)$ is for the universities to adopt a proactive position towards KS. However, as if to compensate for this lack, (35.7\%) engage in informal discussions on academic issues.

Although privacy is not an issue, $47.3 \%$ do not feel compelled to share ideas with others due to the existing KS culture (or lack thereof). $43.6 \%$ trust the accuracy and truthfulness of the knowledge shared. In the same context, $49.1 \%$ worry that their ideas are at risk of plagiarism. Despite these indices, $67.3 \%$ feel that KS decreases competitiveness, whereas a combined $87.2 \%$ share with those with whom a personal relationship exists.

In a university setting, members express and share knowledge. Andrews and Delahaye (2000) suggest that there exist groupings of factors that influence KS. Included are the unwillingness or the capability to share (Foss and Pedersen,
2002), incentive (Gupta and Govindarajan, 2000) and trust towards the receiving group (Davenport and Glaser, 2002; McDermott and O'Dell, 2001). The latter may also determine the level of candidness in sharing (Nahapiet and Ghoshal, 1998).

In view of the perceived lack of motivation and encouragement to transfer and share knowledge, $63.6 \%$ cite rewards as a possible incentive. With the increase of the number of courses available in languages other than Czech, issues arise depending on the individual level of competency and fluency in that language. $41.8 \%$ of respondents claim that linguistic barriers diminish their KS skills.

Recognising that the audience is purely academic set in a university environment wherein $\mathrm{KM}$ courses are offered, $41.8 \%$ cite that it is a foreign concept not suitable for conditions in the Czech Republic. Bureš (2003) identifies a number of cultural barriers although pertinent to enterprise they are also prevalent within an academic setting, a conflict of motives based on one of the assumptions that most individuals perceive $\mathrm{KS}$ as a disagreeable experience that in turn produces conflicting circumstances.

Students demonstrate dissatisfaction with their universities' methods of KS and KT. This for a number of reasons but primarily they claim that their academic environment does not promote or provide sufficiently a forum from which there is a sharing of new ideas. There is agreement that the course content deals with theory and lacks practicality needed in today's competitive market.

As for the technology used for KM purposes, a more dynamic platform is needed; however, this will not increase KS and/or KT participation. This result indicates the existence of another malaise of greater importance. Brelade and Harman (2000) suggest that KM changes the role of the manager from a controller to the one of a facilitator. To a large degree, KM transforms the role of educator to facilitator as well. "Moreover, in the Knowledge Economy students need to learn how to learn and how to manage their own learning, which amounts to a new form of curriculum designed to 
support 'lifelong learning'" (OECD, 2000:37)

University members do share and transfer knowledge but only within select groups. They anticipate a more practical position from their administrators to lead by example in sharing. There lacks suitable rewards programmes. The necessary dynamics are lacking. Their existence is imperative before they view both the quality and nature of the knowledge content as adequate. Although new ideas and methods are abundant, the students remain reluctant to share. The lack of recognition reinforces this reluctance. Although privacy issues are not an obstacle to KS, distrust of knowledge sources, loss of competitiveness, the possibility of plagiarism, and the lack of rewards remain barriers. "Trust lubricates cooperation and cooperation breeds trust" (Nahapiet and Ghoshal, 1998:252).

\section{Conclusions}

Obviously, there exists a direct link between corporate culture and KS as it was concluded in earlier discussion based on the survey (Brunet-Thornton and Bureš, 2012). In addition, among those canvassed, the notion that knowledge equates to power was prevalent. Without development or deployment plans, there is a lack of buy-in that in turn raises suspicions of job loss and resulting redundancies. The study also revealed that the respondents held a negative view on KS in situation when the expertise is threatened. The same is applied to the case when the value seniority contributes to employees' well-being in relation to finances and status. Other elements of corporate culture such as openness and communication play an integral role. The study identified that the vast majority consider KS as a technological advantage of advanced IT systems.

The study confirmed the earlier findings of culture versus KS. These prove that not only social inhibitors play a predominant role, but also motivation should be taken into account (Bureš and Brunet-Thornton, 2009). Modifying corporate structures to embody KS must entail change management in pursuit to properly educate employees, resolve their issues linked with resistance, and change behaviours (Dalkir, 2005). A corporate culture wherein rewards are attributed to senior members or experts does not convey an environment conducive to KS (Dalkir, 2005).

Finally, the study concludes that "there is an unequivocal need for rust and curiosity" (Brunet-Thornton and Bureš, 2012). KS and $\mathrm{KM}$ in general are interrelated. Obviously, without a purposeful management policy of knowledge, the sharing of the latter becomes haphazard and dependent solely on the individuals involved.

\section{Acknowledgment}

Financial support of the GAČR scientific project GA15-11724S DEPIES - Decision Processes in Intelligent Environments is gratefully acknowledged.

\section{References}

1. Andrews, K.M. and Delahaye, B. (2000), 'Influences on Knowledge Processes in Organizational Learning: The Psychosocial Filter,' Journal of Management Studies, 37(6), 797-810.

2. Brelade, S. and Harman, C. (2000), 'Using Human Resources to Put Knowledge to Work,' Knowledge Management Review, 3(1), 26-29.

3. Brunet-Thornton, R. and Bureš, V. (2012), 'The Cross-Cultural Management: Establishing a Czech Benchmark,' $E+M$ Ekonomie a Management, 15(3), 46-62.

4. Brunet-Thornton, R. and Bureš, V. (2013), 'When Knowledge Management Collides with National Culture: EastEuropean knowledge management (or lack thereof?),' Actual Problems of Economics, 8(146), 224-235.

5. Bureš, V. and Brunet-Thornton, R. (2009), 'Knowledge Management: The Czech Situation, Possible Solutions and the Necessity for Further Research,' Proceedings of the 6th International Conference on Intellectual Capital and Knowledge Management, ISBN: 978-1- 
906638-45-0, 1-2 October 2009, Montréal, Canada, 95-102.

6. Bureš, V. (2003), 'Cultural Barriers in Knowledge Sharing,' E+M Ekonomie a Management, 6(special issue), 57-62.

7. Bureš, V., Jašíková, V., Otčenášková, T., Kolerová, K., Zubr, V. and Marešová, P. (2012), 'A Comprehensive View on Evaluation of Cluster Initiatives,' Proceedings of the 8th European Conference on Management Leadership and Governance, ISBN: 978-1-908272-768, 8-9 November 2012, Pafos, Cyprus, 7479.

8. Cameron, K.S. and Quinn, R.E. (1999) Diagnosing and changing organizational culture, Addison-Wesley, Reading.

9. Choo, C.W., Bergeron, P., Detlor, B. and Heaton, L. (2008), 'Information culture and information use: An exploratory study of three organizations,' Journal of the American Society for Information Science and Technology, 59(5), 792-804.

10. Dalkir, K. (2005) Knowledge Management in Theory and Practice, Butterworth-Heinemann, Burlington.

11. Davenport, T.H. and Glaser J. (2002), 'Just-in-time delivery comes to knowledge management,' Harvard Business Review, 80(7), 107-111.

12. Deal, T.E. and Kennedy, A.A. (1982) Corporate Cultures: The Rites and Rituals of Corporate Life, Penguin Books, Harmondsworth.

13. Drucker, P.F. (1996) Landmarks of Tomorrow, Transaction Publishers, Piscataway.

14. Eisenhardt, K.M. and Santos, F.M. (2002), Knowledge-based view: A new theory of strategy?, Handbook of Strategy and Management, Pettigrew, A., Thomas, H. and Whittington, R. (eds.), 139-164, Sage, London.

15. Foss, N. and Pedersen, T. (2002), 'Transferring Knowledge in MNCs: The Roles of Sources of Subsidiary Knowledge and Organizational Context,' Journal of International Management, 8, 1-19.
16. Girard, J.P. and Allison, M. (2008), 'Information Anxiety: Fact, Fiction, or Fallacy?,' Electronic Journal of Knowledge Management, 6(2), 125-140.

17. Gupta, A.K. and Govindarajan, V. (2000), 'Knowledge Flows within Multinational Corporations,' Strategic Management Journal, 21, 473-496.

18. Harrison, R. (1972), 'Understanding your organization's character,' Harvard Business Review, May-June, 19-28.

19. Martín, A., León, C., Luque, J. and Monedero, I. (2012), 'A framework for development of integrated intelligent knowledge for management of telecommunication networks,' Expert Systems with Applications, 39(10), 92649274.

20. McDermott, R. and O'Dell, C. (2001), 'Overcoming Cultural Barriers to Sharing Knowledge,' Journal of Knowledge Management, 5(1), 76-85.

21. Milosz, M. and Milosz, E. (2010), 'Critical Success Factors and Barriers to Implementation of Knowledge Management Systems at Polish SMEs,' Actual Problems of Economics, 108, 309315.

22. Mooradian, T.A., Renzl, B. and Matzler, K. (2006), 'Who trusts? Personality, trust and knowledge sharing,' Management Learning, 37(4), 523-540.

23. Mueller, J. (2014), 'A specific knowledge culture: Cultural antecedents for knowledge sharing between project teams,' European Management Journal, 32(2), 190-202.

24. Nahapiet, J. and Ghoshal, S. (1998), 'Social capital, intellectual capital, and the organizational advantage,' Academy of Management Review, 23(2), 242-266.

25. OECD (2000), 'Knowledge Management in the Learning Society,' Organization for Economic Cooperation and Development. [Online], [Retrieved October 25, 2015], http://ocw.metu.edu.tr/file.php/118/Wee k11/oecd1.pdf 
26. Schein, E.H. (2004) Organizational Culture and Leadership, John Wiley, San Francisco.

27. Shan, S., Zhao, Q. and Hua, F. (2013), 'Impact of quality management practices on the knowledge creation process: The Chinese aviation firm perspective,' Computers \& Industrial Engineering, 64(1), 211-223.

28. Wurman, R. (1989) Information Anxiety, Doubleday, New York.
29. Zaghloul, R. and Hartman, F. (2003), 'Construction contracts: the cost of mistrust,' International Journal of Project Management, 21(6), 419-424.

30. Zheng, W., Yang, B. and McLean, G.N. (2010), 'Linking organizational culture, structure, strategy, and organizational effectiveness: Mediating role of knowledge management,' Journal of Business Research, 63(7), 763-771. 